\title{
Micellar casein concentrate production with a 3X, 3-stage, uniform transmembrane pressure ceramic membrane process at $50^{\circ} \mathrm{C}^{1}$
}

\author{
E. Hurt, ${ }^{\star}$ J. Zulewska, $†$ M. Newbold, ${ }^{*}$ and D. M. Barbano*² \\ *Northeast Dairy Foods Research Center, Department of Food Science, Cornell University, Ithaca, NY 14853 \\ †Faculty of Food Sciences, University of Warmia and Mazury, Olsztyn, Poland
}

\begin{abstract}
The production of serum protein (SP) and micellar casein from skim milk can be accomplished using microfiltration (MF). Potential commercial applications exist for both SP and micellar casein. Our research objective was to determine the total SP removal and SP removal for each stage, and the composition of retentates and permeates, for a $3 \times$, continuous bleed-and-feed, 3 -stage, uniform transmembrane pressure (UTP) system with $0.1-\mu \mathrm{m}$ ceramic membranes, when processing pasteurized skim milk at $50^{\circ} \mathrm{C}$ with 2 stages of water diafiltration. For each of 4 replicates, about $1,100 \mathrm{~kg}$ of skim milk was pasteurized $\left(72^{\circ} \mathrm{C}, 16 \mathrm{~s}\right)$ and processed at $3 \times$ through the UTP MF system. Retentate from stage 1 was cooled to $<4^{\circ} \mathrm{C}$ and stored until the next processing day, when it was diluted with reverse osmosis water back to a $1 \times$ concentration and again processed through the MF system (stage 2) to a $3 \times$ concentration. The retentate from stage 2 was stored at $<4^{\circ} \mathrm{C}$, and, on the next processing day, was diluted with reverse osmosis water back to a $1 \times$ concentration, before running through the MF system at $3 \times$ for a total of 3 stages. The retentate and permeate from each stage were analyzed for total nitrogen, noncasein nitrogen, and nonprotein nitrogen using Kjeldahl methods; sodium dodecyl sulfate-PAGE analysis was also performed on the retentates from each stage. Theoretically, a 3 -stage, $3 \times$ MF process could remove $97 \%$ of the SP from skim milk, with a cumulative SP removal of 68 and $90 \%$ after the first and second stages, respectively. The cumulative SP removal using a 3-stage, $3 \times$ MF process with a UTP system with $0.01-\mu \mathrm{m}$ ceramic membranes in this experiment was $64.8 \pm 0.8,87.8 \pm 1.6$, and $98.3 \pm 2.3 \%$ for the first, second, and third stages, respectively, when calculated using the mass of SP removed in the permeate of each
\end{abstract}

\footnotetext{
Received February 14, 2010.

Accepted August 9, 2010.

${ }^{1}$ Use of names, names of ingredients, and identification of specific models of equipment is for scientific clarity and does not constitute any endorsement of product by authors, University of Warmia and Mazury (Olsztyn, Poland), Cornell University (Ithaca, NY), or the Northeast Dairy Foods Research Center (Ithaca, NY).

${ }^{2}$ Corresponding author: dmb37@cornell.edu
}

stage. Various methods of calculation of SP removal were evaluated. Given the analytical limitations in the various methods for measuring SP removal, calculation of SP removal based on the mass of SP in the skim milk (determined by Kjeldahl) and the mass SP present in all of the permeate produced by the process (determined by Kjeldahl) provided the best estimate of SP removal for an MF process.

Key words: microfiltration, flux, serum protein, protein fractionation

\section{INTRODUCTION}

Casein micelles and serum proteins (SP) in skim milk can be separated by microfiltration (MF). This separation is possible because of the approximately 10to 100-fold difference in diameter between CN micelles and SP (Walstra et al., 1999). A limitation of MF is membrane fouling, which reduces flux and can decrease transmission of SP (Sachdeva and Buchheim, 1997). One technique to minimize fouling is the use of crossflow filtration, in which the retentate is pumped tangentially across the surface of the membrane. Increased flux seen in cross-flow filtration can be explained by the decrease in concentration polarization layer and lifting of solute particles away from the membrane surface due to shear at the membrane surface (Belfort et al., 1994). Le Berre and Daufin (1996) characterized the relationship between flux and shear rate at the membrane surface during $\mathrm{MF}$ of skim milk to separate $\mathrm{CN}$ micelles from SP. They found a critical ratio of flux to shear stress of $1.0 \mathrm{~L} / \mathrm{h}$ per $\mathrm{m}^{2}$ per Pa, where the pressure is the pressure decrease from the inlet to outlet of the membrane when operating a uniform transmembrane pressure (UTP) system at a concentration factor (CF) of $2 \times$ at $50^{\circ} \mathrm{C}$, and that operating above this ratio led to decreased SP transmission and increased fouling.

In a standard cross-flow MF module a pressure drop will occur along the length of the membrane on the retentate side in the direction of fluid flow; in contrast, pressure on the permeate side of the membrane is relatively constant along the length of the membrane. This means the transmembrane pressure (TMP) and 
thus flux at the membrane inlet is higher than at the outlet and varies along the length of the membrane. No matter what operating conditions are chosen, parts of the membrane could be operating under nonideal conditions, leading to excessive fouling congruent with the concept of a critical flux to shear ratio. A solution to this problem was developed by Sandblom (1978), in which the permeate was recirculated on the permeate side of the membrane in the same direction as the retentate flow. The recirculation of permeate creates a pressure decrease on the permeate side of the membrane from inlet to outlet mirroring the pressure drop on the retentate side from inlet to outlet, creating UTP along the membrane's length (and uniform flux).

A UTP system requires membranes that are rigid and self-supporting, because they must be able to handle back pressure. This requirement rules out the use of most polymeric membranes, including spiral-wound membranes, in the UTP approach (Cheryan, 1998). Tubular ceramic membranes have been used successfully in UTP systems to separate CN micelles from SP (Nelson and Barbano, 2005; Zulewska et al., 2009). Some of the earliest published work was done by Pierre et al. (1992), using 0.2- $\mu \mathrm{m}$ ceramic membranes and concentrating skim milk to $3 \times$ before diafiltering. They found that removal of serum proteins from skim milk approached theoretical values. Le Berre and Daufin (1996) found that under optimal operating conditions, transmission of SP was 70 to $80 \%$, and $>99 \%$ of the CN was retained using a $0.1-\mu \mathrm{m}$ ceramic UTP system where skim milk was concentrated to $2 \times$ at $50^{\circ} \mathrm{C}$. Nelson and Barbano (2005) used a 3 -stage, $3 \times$ UTP MF process with $0.1-\mu \mathrm{m}$ ceramic membranes, with dilution using UF permeate between stages. They found an overall SP removal of $95 \%$ after 3 stages.

Both the micellar CN concentrate and SP separated by MF have the potential to be valuable products. The SP has been further purified by ultrafiltration to produce SP concentrates. Serum protein concentrates lack the glycomacropeptides present in whey protein concentrates and have a lower concentration of lipids (Evans et al., 2009). Serum protein isolates exhibit better foaming and gelling properties compared with whey protein concentrates (Britten and Pouliot, 1996). In addition, whey protein concentrates have been found to have diacetyl flavors that SP concentrates lack (Evans et al., 2009).

The micellar CN concentrate could be used to increase cheese yields and revenue (Papadatos et al., 2003) or potentially in food ingredient applications where caseinates are currently used. A single-stage UTP MF process with a $\mathrm{CF}$ of 3 using $0.1-\mu \mathrm{m}$ ceramic membranes can remove $>60 \%$ of the SP from the micellar CN (Nelson and Barbano, 2005; Zulewska et al., 2009); however, there could be advantages to using multiple stages to remove a greater percentage of SP, soluble minerals, and lactose from the micellar $\mathrm{CN}$ concentrate. Casein micelles are very heat stable (Holt, 1992, p.133), whereas whey proteins are not as heat stable and begin denaturing at $70^{\circ} \mathrm{C}$ (de Wit and Klarenbeck, 1984). Lactose also undergoes thermal degradation including Maillard reactions with proteins that can lead to off-flavors and browning (Walstra et al., 1999).

Theoretically, $97 \%$ of the SP should be removed from skim milk in a 3 -stage, $3 \times$ MF process, but the actual removal and yield of micellar $\mathrm{CN}$ concentrate can be influenced by several operational parameters (Hurt and Barbano, 2010). No published research has determined the actual amount of SP, relative to theoretical values, that can be removed in a 3-stage UTP MF process with water diafiltration between stages. Our objective was to determine the total SP removal and the SP removal for each stage for a $3 \times$ continuous bleed-and-feed, 3 -stage UTP system with $0.1-\mu \mathrm{m}$ ceramic membranes, when processing pasteurized skim milk at $50^{\circ} \mathrm{C}$ with 2 stages of water diafiltration.

\section{MATERIALS AND METHODS}

\section{Experimental Design and Statistical Analysis}

One lot of bovine milk (approximately 1,099 kg) was separated in the Cornell University dairy plant at $4^{\circ} \mathrm{C}$ using a model 590 Air Tight centrifuge (DeLaval Co., Chicago, IL). Raw skim milk was pasteurized with a plate heat exchanger with 3 sections: regeneration, heating, and cooling (model 080-S, AGC Engineering, Manassas, VA) at $72^{\circ} \mathrm{C}$ with a holding time of $16 \mathrm{~s}$. Temperature was kept at a minimum for pasteurization to minimize denaturation of SP. The milk was cooled to $4^{\circ} \mathrm{C}$ and stored at $\leq 4^{\circ} \mathrm{C}$ until processing. On d 1 , pasteurized skim milk was heated to $50^{\circ} \mathrm{C}$ with a plate heat exchanger (model A3, DeLaval Inc., Kansas, MO) and microfiltered using a pilot-scale ceramic UTP system in bleed-and-feed mode to continuously produce a $3 \times \mathrm{MF}$ retentate and $\mathrm{MF}$ permeate at $50^{\circ} \mathrm{C}$. The $\mathrm{MF}$ retentate was cooled to $\leq 4^{\circ} \mathrm{C}$ as it was collected and stored until the next processing day. On the second day, MF retentate from the first day was diluted back to a $1 \times$ concentration ( $2 \mathrm{~kg}$ of water for every $1 \mathrm{~kg}$ of retentate) with pasteurized reverse osmosis (RO) water, heated to $50^{\circ} \mathrm{C}$, and diafiltered with the ceramic UTP MF system to produce a $3 \times$ retentate. On the third day, this diafiltration procedure was repeated to complete a 3 -stage process. This process was replicated 4 times starting with different batches of raw milk.

Data were analyzed by ANOVA using the Proc GLM procedures of SAS (version 8.02 1999-2001, SAS Insti- 
tute Inc., Cary, NC). To determine if significant differences existed due to stage of MF, the GLM model used was dependent variable $=$ Stage + Replicate + Error . To determine if significant differences existed between the different methods used to calculate SP removal, the GLM was SP removal $=$ Method + Replicate + Error .

\section{Microfiltration Operation}

A pilot-scale UTP MF system (Tetra Alcross M7, TetraPak Filtration Systems, Aarhus, Denmark) equipped with ceramic Membralox (EP1940GL0.1 $\mu$ A, alumina, Pall Corp., Cortland, NY) membranes (pore diameter: $0.1 \mu \mathrm{m}$; surface area: $1.7 \mathrm{~m}^{2}$ ), and variable area flow meters were used. The membranes in a tubular stainless module consisted of 7 ceramic tubes, with 19 channels each with a $4-\mathrm{mm}$ channel diameter. The permeate section of the stainless steel module was filled with polymeric beads ( 3.72 to $3.78 \mathrm{~mm}$ in diameter) to reduce dead volume, act as buffer for pressure changes, and produce a larger pressure decrease from inlet to outlet on the permeate side of the membrane. The UTP MF system consisted of a feed pump (type LKH 10/110 SSS $1.75 \mathrm{~kW}$ ), a retentate recirculation pump (type LKH 20/125 SSS $6.3 \mathrm{~kW}$ ), and a permeate recirculation pump (type LKH 10/130 SSS $2.5 \mathrm{~kW}$ ) all from Alfa Laval (Kansas City, MO). The membranes were $1.02 \mathrm{~m}$ long and were mounted vertically in the MF system with permeate and retentate flow co-current from the top to the bottom of the module. Because the membrane was mounted vertically, the inlet and outlet gauge pressures had to be corrected for the difference due to the weight of the vertical column of liquid. The correction was measured as follows: with $50^{\circ} \mathrm{C} \mathrm{RO}$ water in the system and only the feed pump turned on, the retentate and permeate outlet valves were closed. Retentate inlet pressure $\left(\mathbf{R} \mathbf{p}_{\mathbf{i}}\right)$, permeate inlet pressure $\left(\mathbf{P p}_{\mathbf{i}}\right)$, retentate outlet pressure $\left(\mathbf{R}_{\mathbf{p}_{\mathbf{o}}}\right)$, and permeate outlet pressure $\left(\mathbf{P p}_{\mathbf{o}}\right)$ were measured under these conditions. A correction factor for calculating transmembrane pressure was calculated for each gauge pressure as follows: the $R p_{i}$ gauge pressure correction was $\mathrm{Pp}_{\mathrm{o}}-\mathrm{R} \mathrm{p}_{\mathrm{i}}$, the $R p_{o}$ gauge pressure correction was $\mathrm{Pp}_{\mathrm{o}}-\mathrm{Rp}_{\mathrm{o}}$, the $\mathrm{Pp}_{\mathrm{i}}$ gauge pressure correction was $\mathrm{Pp}_{o}-\mathrm{Pp}_{\mathrm{i}}$, and the $\mathrm{Pp}_{\mathrm{o}}$ gauge pressure correction was zero. This correction factor was determined at the beginning of each run of each stage. Next, retentate and permeate recirculation pumps were turned on and the retentate bleed flow was set to $45 \mathrm{~L} / \mathrm{h}$ and the permeate bleed flow was set to 90 $\mathrm{L} / \mathrm{h}$. The elevation-corrected inlet and outlet pressures were measured and the transmembrane pressure from the retentate to the permeate side of the membrane at retentate inlet $\left(\mathbf{T} \mathbf{M} \mathbf{P}_{\mathbf{i}}\right)$ and outlet $\left(\mathbf{T M P} \mathbf{P}_{\mathbf{o}}\right)$ ends of the membrane were calculated. The goal was to have a pressure differential $\left(\Delta \mathrm{P}=\mathrm{TMP}_{\mathrm{i}}-\mathrm{TMP}_{\mathrm{o}}\right)$ of $25 \pm$ $3 \mathrm{kPa}$ for a membrane length of $1.02 \mathrm{~m}$. A diaphragm valve in the permeate recirculation loop was used to adjust the recirculation flow rate on the permeate side of the membrane. The permeate recirculation flow rate was adjusted with the diaphragm valve until the $\Delta \mathrm{P}$ was $25 \pm 3 \mathrm{kPa}$.

Cleaning Before Processing. Immediately before processing on each day, the MF system was cleaned. Storage solution $(0.55 \% \mathrm{vol} / \mathrm{vol}$ solution of nitric acid $)$ was flushed out of the system with room temperature $\mathrm{RO}$ water until the $\mathrm{pH}$ was neutral. The MF flow system was heated with $\mathrm{RO}$ water to $80^{\circ} \mathrm{C}$ and then Ultrasil 25 (Ecolab Inc., Food and Beverage Division, St Paul, $\mathrm{MN})$ liquid alkaline membrane cleaner $(1.95 \% \mathrm{vol} / \mathrm{vol})$ was added to the water to reach $\mathrm{pH} 11$. The alkaline solution was recirculated for $25 \mathrm{~min}$ at a permeate removal rate of approximately $1,000 \mathrm{~L} / \mathrm{h}$, and retentate removal rate of approximately 160 to $180 \mathrm{~L} / \mathrm{h}$, with all pumps running. After cleaning, the membrane system was slowly $\left(<10^{\circ} \mathrm{C}\right.$ per min) cooled to $50^{\circ} \mathrm{C}$ with the tubular heat exchanger in the recirculation loop. The MF system was then flushed with RO water (about 300 $\mathrm{kg}$ at $30^{\circ} \mathrm{C}$ ) until neutral $\mathrm{pH}$ was reached. The membrane was flushed with $50^{\circ} \mathrm{C} \mathrm{RO}$ water until the system temperature was $50^{\circ} \mathrm{C}$ (about $60 \mathrm{~kg}$ ) and the initial clean water flux was determined. The following conditions were applied during the flux measurement: the retentate outlet valve was closed and permeate outlet valve was fully open with only the feed pump running.

First Stage: Day 1. Skim milk (about 1,099 kg) was processed to approximately a $3 \times \mathrm{CF}$ at $50^{\circ} \mathrm{C}$ using a pilot-scale UTP MF system described above (a $3 \times \mathrm{CF}$ being $2 \mathrm{~kg}$ of permeate removed for every 1 $\mathrm{kg}$ of retentate). The system was started on $50^{\circ} \mathrm{C} \mathrm{RO}$ water and there was a transition from water to milk with all the pumps running; the recirculation rate was approximately $644 \mathrm{~L} / \mathrm{min}$ with a linear velocity of approximately $6.4 \mathrm{~m} / \mathrm{s}$. To flush the $50^{\circ} \mathrm{C}$ water out of the system with milk at the beginning of the process, about $14 \mathrm{~kg}$ of retentate and $31 \mathrm{~kg}$ of permeate were collected, the weights were recorded, and both were discarded (mostly water). After this start up, retentate and permeate were collected continuously and cooled to $4^{\circ} \mathrm{C}$ as they were collected. Retentate and permeate removal rates were 45 and $90 \mathrm{~L} / \mathrm{h}$, respectively. If the $\Delta \mathrm{P}$ was not $25 \pm 3 \mathrm{kPa}$ after switching from water to milk, then the permeate recirculation diaphragm valve was adjusted while processing skim milk to achieve and maintain this TMP difference between the outlet and inlet ends of the membrane. Typical $R p_{i}$ and $P p_{i}$ pressures (without the correction factors) were 419.8 and $387.5 \mathrm{kPa}$, respectively, and typical $\mathrm{Rp}_{\mathrm{o}}$ and $\mathrm{Pp}_{\mathrm{o}}$ pressures were 229.8 and $218.8 \mathrm{kPa}$, respectively. The 
flux $\left(\mathrm{kg} / \mathrm{m}^{2}\right.$ per hour) was measured every $15 \mathrm{~min}$, and samples of permeate and the retentate were taken for analysis using an infrared spectrophotometer (Lactoscope FTIR, Delta Instruments, Drachten, the Netherlands) to monitor retentate and permeate composition for process control. At the end of the MF run, the collected retentate and permeate were mixed separately and sampled.

Second Stage: Day 2. The second-stage feed of the 3 -stage process was the retentate from the first stage diluted by weight: $2 \mathrm{~kg}$ of pasteurized $\mathrm{RO}$ water for every $1 \mathrm{~kg}$ of retentate (about $320 \mathrm{~kg}$ of retentate and $640 \mathrm{~kg}$ of water); this is a diafiltration factor (DF) of 3. Retentate and water were mixed before heating to $50^{\circ} \mathrm{C}$ and processed with the MF UTP system using the same operating conditions as described for the first stage. All retentate was collected, cooled, mixed, and sampled. Permeate was weighed, sampled (every 15 min), and discarded. A composite sample of permeate was used for analysis.

Third Stage: Day 3. The third stage of the 3-stage process was as described for the second stage, with the feed being the retentate from the second stage diluted with RO water (about $274 \mathrm{~kg}$ of retentate and $549 \mathrm{~kg}$ of water). The amount of retentate decreased from stage to stage because of the loss of retentate as the dead volume of the system when ending the previous stage. The average total time of processing was about $497 \mathrm{~min}$ for the first stage, $428 \mathrm{~min}$ for the second stage, and 343 min for the third stage.

Cleaning After Processing. Immediately after processing, $50^{\circ} \mathrm{C} \mathrm{RO}$ water $(150$ to $200 \mathrm{~L}$ ) was flushed through the system with all pumps on. The retentate and permeate removal rates were set at approximately 160 and $120 \mathrm{~L} / \mathrm{h}$, respectively. The MF system was flushed until no retentate was visible in the flush water on the retentate side. When the water flush was complete, the fouled membrane water flux was determined (retentate outlet valve closed, permeate outlet valve completely open, only the feed pump on with temperature maintained at $50^{\circ} \mathrm{C}$ ). Typically, fouled membrane flux was about $46 \%$ of the clean membrane water flux (1,065 vs. $491 \mathrm{~kg} / \mathrm{m}^{2}$ per hour). Next, the MF flow system was heated with $\mathrm{RO}$ water to $80^{\circ} \mathrm{C}$. Ultrasil 25 liquid alkaline membrane cleaner (Ecolab Inc.) was added (1.95\% $\mathrm{vol} / \mathrm{vol}$ ) to the water to reach $\mathrm{pH} 11$. This solution was recirculated for $25 \mathrm{~min}$ with the permeate and retentate exit flows at approximately $1,000 \mathrm{~L} / \mathrm{h}$ and 160 to 180 $\mathrm{L} / \mathrm{h}$, respectively, with all pumps on. After cleaning, the membrane system was slowly $\left(<10^{\circ} \mathrm{C}\right.$ per min) cooled to $50^{\circ} \mathrm{C}$ with the heat exchanger on retentate recirculation loop. The membrane was then flushed with approximately $30^{\circ} \mathrm{C} \mathrm{RO}$ water until neutral $\mathrm{pH}$ was reached. The MF flow system was heated to $50^{\circ} \mathrm{C}$ by flushing with $50^{\circ} \mathrm{C} \mathrm{RO}$ water and the post-run clean water flux was determined. During flux determination, the retentate outlet valve was closed and the permeate outlet valve was fully open with only the feed pump on and the temperature maintained at $50^{\circ} \mathrm{C}$. The post-run clean water fluxes were also close to pre-run clean water flux (i.e., about 1,050 to $1,070 \mathrm{~L} / \mathrm{m}^{2}$ per hour). After determination of clean water flux, a $0.55 \%$ ( $\mathrm{vol} / \mathrm{vol}$ ) solution of $70 \%$ nitric acid and water was recirculated through the membrane at $50^{\circ} \mathrm{C}$ for $10 \mathrm{~min}$. Permeate and retentate outlet flows were approximately 1,000 $\mathrm{L} / \mathrm{h}$ and 160 to $180 \mathrm{~L} / \mathrm{h}$, respectively. After $10 \mathrm{~min}$ of nitric acid solution recirculation, the permeate and retentate outlet valves were closed and the pumps turned off. The membrane was stored in $0.55 \%$ ( vol/vol) nitric acid solution.

\section{Chemical Analyses}

Samples of skim milk, permeate, and retentate collected during processing were analyzed using an infrared spectrophotometer (Lactoscope FTIR, Delta Instruments) for fat, lactose, and true protein content (Kaylegian et al., 2006). This was done to quickly monitor the composition of retentate and permeate during the run to detect if the system was running normally.

Skim milk, retentate, and permeate for each stage were analyzed for TS, total N (TN), and NPN content using forced-air oven drying (AOAC, 2000; method 990.20; 33.2.44), Kjeldahl (AOAC, 2000; method 991.20; 33.2.11), and Kjeldahl (AOAC, 2000; method 991.21; 33.2.12), respectively. The noncasein nitrogen (NCN) content of retentates was determined using Kjeldahl (AOAC, 2000; method 998.05; 33.2.64). True protein (TP) was calculated by subtracting NPN from TN and multiplying by 6.38 ; $\mathrm{CN}$ was calculated by subtracting the NCN from TN and multiplying by 6.38 ; and SP content was calculated by subtracting NPN from NCN and multiplying by 6.38 . The SP content in the permeate portion of the skim milk (expressed as a percentage) was calculated by dividing mass of SP in $1 \mathrm{~kg}$ of milk by the permeate portion of the milk multiplied by 100 , where the permeate portion of milk is $1 \mathrm{~kg}$ minus the weight of CN in $1 \mathrm{~kg}$ of skim milk.

SP Removal Estimation Using Kjeldahl Analysis of Permeates. The SP removal for each stage was estimated using Kjeldahl analysis (TN and NPN) of permeates. Serum protein removal equaled the percentage of SP in the original skim milk removed in each stage. It was calculated by dividing the mass of $\mathrm{TP}$ (TP concentration was calculated from TN and NPN concentrations obtained by Kjeldahl analysis of the permeates, and mass of TP was calculated by multiplying the concentration of TP by the mass of permeate) 
in the permeate of each stage by the mass of SP in the starting skim milk times 100 .

Theoretical values for removal were calculated using the above equations assuming that $\mathrm{CN}$ was $100 \%$ retained and that the concentration of SP in the permeate equaled the concentration of SP in the permeate phase of skim milk or water diluted retentate feed and that the CF and DF were both exactly 3 .

SP Removal Estimation Using Kjeldahl Analysis of Retentates. For each stage, TN, NCN, and NPN concentrations obtained by Kjeldahl analysis of retentates were used to calculate SP and CN concentration in retentates. Serum protein removal based on Kjeldahl analysis of retentates was then calculated as 100 times the ratio of SP to CN in retentate subtracted from the SP to $\mathrm{CN}$ ratio in skim milk, with the result divided by the ratio of SP to CN in skim milk.

\section{Particle Size Analysis of Skim Milk and Retentate}

Particle size distribution was measured using a Mastersizer 2000 with a Hydro 2000-S liquid sample dispersion unit (pump speed 2,250 rpm) with software version 5.40 (Malvern Instruments, Westborough, MA). A combination of a red $(633 \mathrm{~nm})$ and blue laser (466 $\mathrm{nm}$ ) were used. The sample material refractive index was set at 1.458 and an absorption value of 0.00001 . The blue light refractive index for fat was set at 1.460 with an absorption value of 0.00001 . The dispersant (water) refractive index was set at 1.33 . The density of the particulate material was set at $0.902 \mathrm{~g} / \mathrm{cm}^{3}$. The general-purpose predictive model type was used, with the particle shape set to spherical. The size range of particles to be detected was 0.020 to $2,000 \mu \mathrm{m}$. The obscuration limits were set from 7 to $9 \%$ to achieve a consistent amount of sample loading and to minimize the risk of multiple light scattering. The sample and dispersant temperatures were between 22 and $24^{\circ} \mathrm{C}$. Background and sample measurement time was $5 \mathrm{~s}$ and 5,000 snaps. Three measurement cycles were used with no delay between measurements; the average of the 3 cycles was reported. The majority of samples had residual values for the statistical model between 0.4 and $1 \%$, with occasional samples having residuals between 1 and $2 \%$. The volume mean diameter $(\mathbf{D}[\mathbf{4}, \mathbf{3}])$ and the diameter below which $90 \%$ of the fat was contained $(\mathbf{D}[\mathbf{0 . 9}])$ were reported.

\section{Color Analysis of Retentate}

Hunter L (lightness), a (red-green), and b (yellow-blue) values for the permeates were determined in duplicate with a MacBeth Color-Eye spectrophotometer (model 2020, Kollmorgen Instruments Corp., Newburgh, NY) with Optiview software from the same company. Hunter values were computed from the diffuse reflectance of light in the 360 to $740 \mathrm{~nm}$ range, at 20-nm intervals, based on illuminant $\mathrm{A}$. The measurements were done at 23 to $25^{\circ} \mathrm{C}$ (Quinones et al., 1998). The retentates for color analysis were taken from the complete mixed batch of collected retentate at the end of each stage of processing.

\section{SDS-PAGE}

A 10 to $20 \%$ polyacrylamide gradient was used to determine the relative proportion of protein types in retentates and permeates from $3 \mathrm{MF}$ systems. Retentate samples $(0.1 \mathrm{~mL})$ were diluted with sample buffer $(0.9 \mathrm{~mL})$ consisting of $10 \mathrm{~m} M$ Tris- $\mathrm{HCl} \mathrm{pH} \mathrm{6.8,} 1.0 \%$ SDS, $20 \%$ glycerol, and $0.02 \%$ bromophenol blue tracking dye and $50 \mathrm{mM}$ dithiothreitol and stored frozen $\left(-17^{\circ} \mathrm{C}\right.$ ) in glass vials (Target DP Vials C4000-1W, National Scientific Co., Rockwood, TN) sealed with DP Blue Cap (C4000-51B, National Scientific Co.). Diluted samples were thawed, heated to $100^{\circ} \mathrm{C}$ in a steam chamber, held at $100^{\circ} \mathrm{C}$ for $3 \mathrm{~min}$, and then cooled to about $25^{\circ} \mathrm{C}$. Retentates and milks were loaded, at 10 and 8.5 $\mu \mathrm{L}$, respectively, onto an SDS-PAGE gel (Verdi et al., 1987), and the procedure of Verdi et al. (1987) was used for running, staining, and destaining the gels. Gels were scanned with USB GS 800 Densitometer using Quantity 1 1-D Analysis software (Bio-Rad Laboratories Inc., Hercules, CA) to obtain a relative protein composition of samples. Loading of the samples was chosen to achieve an optical density of the predominant protein in the sample in the range of 1.0 to 1.4. A milk sample was run on each gel as a reference for proper resolution of milk proteins and a check for consistency of quantitative analysis from gel to gel. The background was adjusted separately for each lane using the rolling disk method of subtraction to obtain a flat base on the pop-up trace. The line that defined each lane was adjusted using the lane tool function (add, adjust anchors) in the software so that the lane line crossed each band at the center. The adjust band function of the software was used with brackets to set the leading and trailing edge for each band as visually observed on the image of the gel, not based on the beginning and end of the peak in the pop-up trace. The bracket width was set to include the full width of all bands.

\section{SP Removal Estimation Using SDS-PAGE}

To calculate relative percentage SP removal using SDS-PAGE results, first the SP as a percentage of CN for each lane was calculated, which was the sum of the relative density of all SP bands divided by the sum of 
Table 1. Mean $(n=4)$ transmembrane pressure (TMP) at the membrane inlet and outlet, flux, and concentration factors for each stage of the 3-stage uniform transmembrane ceramic microfiltration (MF) system operational parameters

\begin{tabular}{lcccc}
\hline MF stage & $\begin{array}{c}\text { TMP inlet } \\
(\mathrm{kPa})\end{array}$ & $\begin{array}{c}\text { TMP outlet } \\
(\mathrm{kPa})\end{array}$ & $\begin{array}{c}\text { Flux } \\
\left(\mathrm{kg} / \mathrm{m}^{2} \text { per hour }\right)\end{array}$ & $\begin{array}{c}\text { Concentration } \\
\text { factor }\end{array}$ \\
\hline Stage 1 & 42 & 15 & 54.0 & $3.2^{\mathrm{b}}$ \\
Stage 2 & 42 & 15 & 54.0 & $3.2^{\mathrm{b}}$ \\
Stage 3 & 42 & 16 & 54.6 & $3.3^{\mathrm{a}}$ \\
SE & 0.59 & 0.83 & 0.19 & 0.02 \\
$\mathrm{R}^{2}$ & 0.28 & 0.06 & 0.89 & 0.89 \\
\hline
\end{tabular}

${ }^{\mathrm{a}, \mathrm{b}}$ Means in the same column not sharing a common superscript are different $(P<0.05)$.

relative density of the $\mathrm{CN}$ bands times 100. Calculation of $\mathrm{SP}$ reduction was as follows: $\mathrm{SP}$ reduction $=100 \times$ (\%SP $[$ milk] - \%SP[retentate]) $/ \% \mathrm{SP}[$ milk], where \%SP is either $\mathrm{SP}$ as a percentage of $\mathrm{CN}$ in milk or retentate. The bands corresponding to SP and CN are shown and labeled in Figure 1.

\section{RESULTS AND DISCUSSION}

\section{Processing}

Operational Parameters. No differences in TMP at the inlet and outlet (Table 1) were detected among stages $(P>0.05)$. The TMP pressure at the membrane outlet end was always greater than zero, indicating no reverse flow of permeate back into the retentate side at the outlet. The TMP at the inlet was $27 \mathrm{kPa}$ higher than at the outlet and was within the operational parameter of $25 \pm 3 \mathrm{kPa}$. Flux averaged $54.2 \mathrm{~kg} / \mathrm{m}^{2}$ per hour and no differences were detected in flux $(P>0.05)$ over the 3 stages and 4 replicates. Flux was under direct control and did not decrease during the run.

Concentration Factor. Concentration factors for each stage were higher than $3 \times$ as shown in Table 1 . Dilution of the retentate between stages was independent of actual $\mathrm{CF}$, and $2 \mathrm{~kg}$ of $\mathrm{RO}$ water per $1 \mathrm{~kg}$ retentate was always added. An average flux of 54.2 $\mathrm{kg} / \mathrm{m}^{2}$ per hour corresponds to $92.14 \mathrm{~kg} / \mathrm{h}$ of permeate removal for this system. The retentate removal to achieve the CF in Table 1 would have to have been $<42$ $\mathrm{kg} / \mathrm{h}$. Both permeate and retentate bleed rates were set using volumetric flow meters. No correction in the flow measurement for retentate was made for increases in viscosity as $\mathrm{CF}$ increased, which might explain why we were not able to control CF to exactly $3 \times$ during processing.

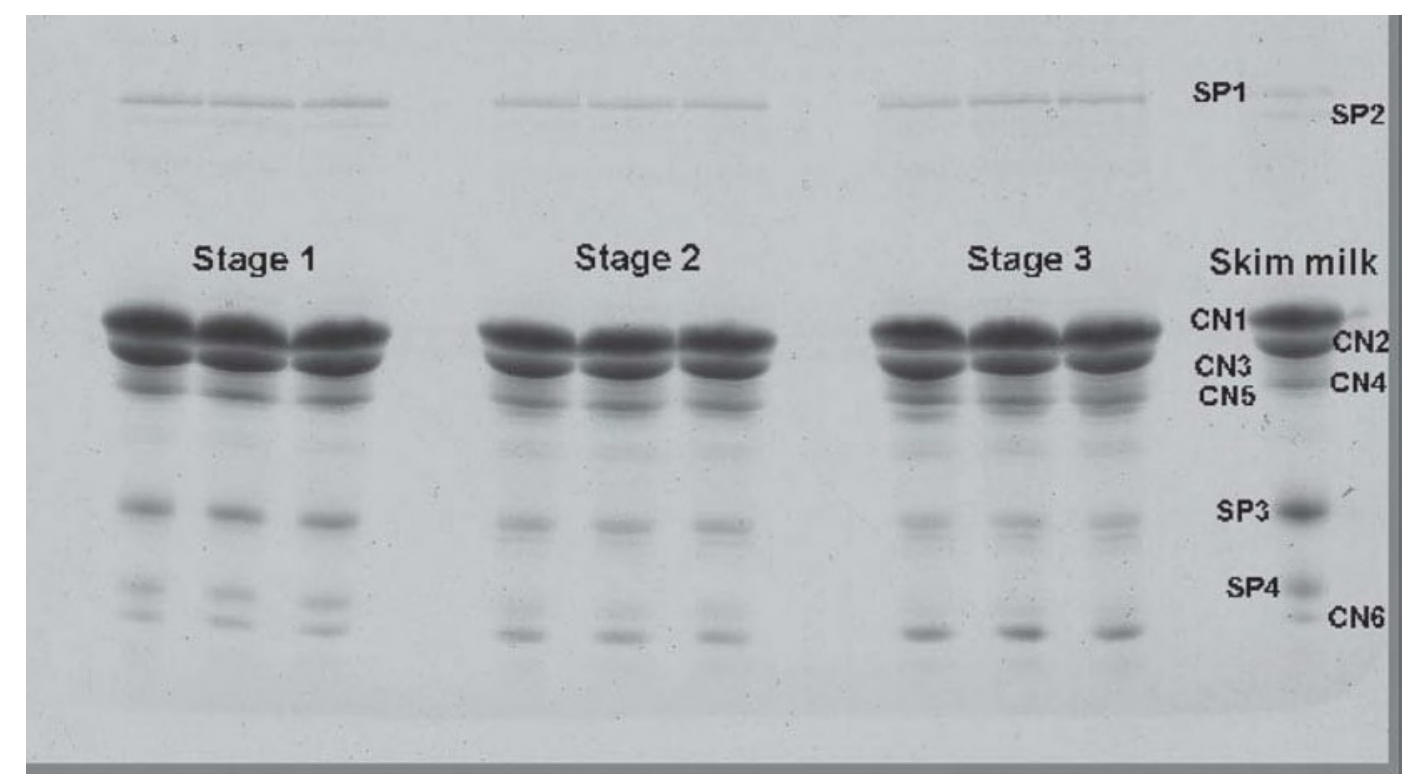

Figure 1. The proteins in skim milk and microfiltration retentates produced in each stage using SDS-PAGE. Bands in skim milk are identified on the gel: SP1, SP2 = serum proteins; CN1 $=\alpha_{S^{-}} \mathrm{CN}$ (combination of $\alpha_{\mathrm{S} 1}$ and $\alpha_{\mathrm{S2}_{2}} \mathrm{CN}$ ); CN2 $=\beta$-casein; CN4 $=\kappa$-casein; CN3 $=$ proteolysis products of casein; CN5 $=$ proteolysis products of casein; SP3 $=\beta-\mathrm{LG} ; \mathrm{SP} 4=\alpha-\mathrm{LA}$; and CN6 $=$ proteolysis products of casein. 
Table 2. Mean $(\mathrm{n}=4)$ composition of pasteurized skim milk (\% by weight)

\begin{tabular}{|c|c|c|c|c|c|c|c|c|}
\hline \multirow[b]{2}{*}{$\begin{array}{l}\text { Pasteurized } \\
\text { skim milk }\end{array}$} & \multicolumn{8}{|c|}{ Composition $^{1}$} \\
\hline & $\mathrm{TN}$ & $\mathrm{NCN}$ & $\mathrm{NPN}$ & $\mathrm{TP}$ & Casein & $\begin{array}{l}\text { Serum } \\
\text { proteins }\end{array}$ & $\begin{array}{l}\text { Serum proteins } \\
\text { in permeate } \\
\text { portion of } \\
\text { skim milk }\end{array}$ & $\begin{array}{c}\text { \% Casein } \\
\text { in TP }\end{array}$ \\
\hline Replicate 1 & 3.33 & 0.74 & 0.18 & 3.15 & 2.59 & 0.56 & 0.57 & 82.13 \\
\hline Replicate 2 & 3.39 & 0.74 & 0.18 & 3.21 & 2.65 & 0.56 & 0.58 & 82.66 \\
\hline Replicate 3 & 3.34 & 0.73 & 0.16 & 3.18 & 2.61 & 0.57 & 0.59 & 82.09 \\
\hline Replicate 4 & 3.30 & 0.73 & 0.19 & 3.11 & 2.57 & 0.54 & 0.55 & 82.63 \\
\hline Mean & 3.34 & 0.73 & 0.18 & 3.16 & 2.60 & 0.56 & 0.57 & 82.38 \\
\hline SD & 0.04 & 0.01 & 0.01 & 0.04 & 0.03 & 0.01 & 0.01 & 0.31 \\
\hline
\end{tabular}

\section{Composition and Color}

Skim Milk Composition. Composition of the protein portion of the 4 batches of skim milk used in the study was very similar (Table 2). Heat treatment of milk can increase the apparent $\mathrm{CN}$ concentration in milk (Lynch et al., 1998). This is caused by SP denaturing and becoming associated with the $\mathrm{CN}$ micelle; specifically, $\beta$-LG forms disulfide bonds with $\kappa$-CN. This bound $\beta-\mathrm{LG}$ is measured as $\mathrm{CN}$ when using Kjeldahl analysis. In Ma et al. (2000), it was reported that in raw milk, CN as a percentage of TP was $82.32 \%$ and that after pasteurization $\left(74^{\circ} \mathrm{C}\right.$ for $\left.34 \mathrm{~s}\right), \mathrm{CN}$ as a percentage of TP increased by $2.89 \%$. In our study, the pasteurization temperature was lower than that used by Ma et al. (2000), and the amount of $\mathrm{CN}$ as a percentage of TP in Table 2 indicates that the milk had not undergone excessive heat treatment and was similar to raw milk.

Permeate Composition. The TS, TN, and NPN concentration in permeate (Table 3) decreased with increasing stage $(P<0.05)$. This was primarily due to the retentate being diluted with water before stages 2 and 3. Permeate from the first stage (Table 3) had a TP concentration similar to the SP concentration in the permeate portion (Table 2 ) of skim milk (0.58 vs.
0.57 , respectively). Theoretically, using the same calculation method as Hurt and Barbano (2010), a $3 \times$ MF process starting with skim milk containing $3.16 \% \mathrm{TP}$ should have a concentration of SP in permeate of 0.58 , 0.18 , and $0.06 \%$ for the first, second, and third stages, respectively. The actual permeate contained $0.58,0.25$, and $0.14 \% \mathrm{TP}$ in each stage, respectively. The higher than theoretical SP concentrations observed for the second and third stages was due, in part, to TP in the permeate being measured instead of SP. Another contribution to higher TP concentration in permeate compared with predicted TP concentration in permeate for the second and third stages was SP rejection by the membrane. If the membrane rejects SP, the concentration of SP in permeate of later stages is expected to be higher than when the membrane does not reject SP (Hurt and Barbano, 2010).

Retentate Composition. Based on the paper by Hurt and Barbano (2010), if both the CF and water DF were 3 given the mean skim milk composition used in the present study $(3.16 \% \mathrm{TP})$, then the concentration of TP in the retentate would decrease slightly from 8.32 to 7.96 to $7.85 \%$ for each of the 3 stages, respectively, because of the removal of SP. An increase in TP concentration in retentate was predicted if the

Table 3. Mean $(\mathrm{n}=4)$ composition (\% by weight) of permeates from each stage of the 3-stage uniform transmembrane ceramic microfiltration (MF) system

\begin{tabular}{lccccc}
\hline & \multicolumn{5}{c}{ Composition $^{1}$} \\
\cline { 2 - 6 } MF stage & $\begin{array}{c}\text { Total } \\
\text { solids }\end{array}$ & Lactose & TN & NPN & TP \\
\hline Stage 1 & $6.53^{\mathrm{a}}$ & $5.01^{\mathrm{a}}$ & $0.76^{\mathrm{a}}$ & $0.18^{\mathrm{a}}$ & $0.58^{\mathrm{a}}$ \\
Stage 2 & $2.09^{\mathrm{b}}$ & $1.62^{\mathrm{b}}$ & $0.31^{\mathrm{b}}$ & $0.06^{\mathrm{b}}$ & $0.25^{\mathrm{b}}$ \\
Stage 3 & $0.73^{\mathrm{c}}$ & $0.61^{\mathrm{c}}$ & $0.17^{\mathrm{c}}$ & $0.03^{\mathrm{c}}$ & $0.14^{\mathrm{c}}$ \\
SE & 0.01 & 0.009 & 0.003 & 0.003 & 0.002 \\
$\mathrm{R}^{2}$ & $>0.99$ & $>0.99$ & $>0.99$ & $>0.99$ & $>0.99$ \\
\hline
\end{tabular}

${ }^{\mathrm{a}-\mathrm{c}}$ Means in the same column not sharing a common superscript are different $(P<0.05)$.

${ }^{1} \mathrm{TN}=$ total nitrogen $\times 6.38 ; \mathrm{NPN}=$ nonprotein nitrogen $\times 6.38 ; \mathrm{TP}=$ true protein $(\mathrm{TN}-\mathrm{NPN})$. 
Table 4. Mean ( $\mathrm{n}=4)$ composition (\% by weight) of the retentates from each stage of the 3-stage uniform transmembrane ceramic microfiltration (MF) system

\begin{tabular}{|c|c|c|c|c|c|c|c|c|}
\hline \multirow[b]{2}{*}{ MF stage } & \multicolumn{8}{|c|}{ Composition $^{1}$} \\
\hline & $\begin{array}{l}\text { Total } \\
\text { solids }\end{array}$ & $\begin{array}{l}\text { Lactose } \\
(\mathrm{IR})^{2}\end{array}$ & $\mathrm{TN}$ & $\mathrm{NCN}$ & NPN & $\mathrm{TP}$ & Casein & $\begin{array}{l}\text { Serum } \\
\text { proteins }\end{array}$ \\
\hline Stage 1 & $15.05^{\mathrm{a}}$ & $4.50^{\mathrm{a}}$ & $8.85^{\mathrm{ab}}$ & $0.95^{\mathrm{a}}$ & $0.17^{\mathrm{a}}$ & $8.67^{\mathrm{b}}$ & $7.90^{\mathrm{b}}$ & $0.78^{\mathrm{a}}$ \\
\hline Stage 2 & $11.41^{\mathrm{b}}$ & $1.38^{\mathrm{b}}$ & $8.68^{\mathrm{b}}$ & $0.56^{\mathrm{b}}$ & $0.07^{\mathrm{b}}$ & $8.61^{\mathrm{b}}$ & $8.13^{\mathrm{b}}$ & $0.49^{\mathrm{b}}$ \\
\hline Stage 3 & $10.80^{\mathrm{c}}$ & $0.40^{\mathrm{c}}$ & $9.12^{\mathrm{a}}$ & $0.45^{\mathrm{c}}$ & $0.04^{\mathrm{c}}$ & $9.08^{\mathrm{a}}$ & $8.68^{\mathrm{a}}$ & $0.40^{\mathrm{c}}$ \\
\hline $\mathrm{SE}$ & 0.097 & 0.006 & 0.086 & 0.017 & 0.003 & 0.086 & 0.074 & 0.016 \\
\hline $\mathrm{R}^{2}$ & $>0.99$ & $>0.99$ & 0.90 & 0.99 & $>0.99$ & 0.90 & 0.95 & 0.98 \\
\hline
\end{tabular}

CF was greater than the water DF (Hurt and Barbano, 2010 ), and a CF of 3.1 and water DF of 3.0 would lead to increasing TP concentration in the retentate of $8.67,8.57$, and $8.73 \%$ for each stage, respectively. The $\mathrm{TP}$ concentration in the retentate for each stage shown in Table 4 indicates no change in TP concentration from stage 1 to 2 and an increase in stage 3, which was consistent with a scenario in which $\mathrm{CF}$ was greater than water DF.

The TS, lactose, TN, NCN, NPN, TP, CN, and SP concentrations in retentate (Table 4) decreased with increasing stage $(P<0.05)$. This decrease was expected because the retentate was diluted with water after stage 1 and 2, and TS, NPN, and SP are removed in permeate. However, based on the theoretical calculations from Hurt and Barbano (2010), if the membrane did not reject $\mathrm{SP}$, then the concentration of $\mathrm{SP}$ in the third-stage retentate should be around $0.1 \%$, not the $0.4 \% \mathrm{SP}$ measured in the third-stage retentate (Table 4). This was because the measured concentration of $\mathrm{SP}$ was overestimated in MF retentates and $\mathrm{CN}$ was underestimated in the MF retentates when using the Kjeldahl NCN method, which was designed for analysis of milk, not retentates, as reported previously by Nelson and Barbano (2005). Noncasein N must be measured to determine both SP and $\mathrm{CN}$ using Kjeldahl analysis. Measured NCN content of a $3 \times$ MF retentate will be erroneously high, which leads to an overestimated SP concentration $[(\mathrm{NCN}-\mathrm{NPN}) \times 6.38]$ and underestimated $\mathrm{CN}$ concentration $[(\mathrm{TN}-\mathrm{NCN}) \times 6.38]$ in $\mathrm{MF}$ retentates when the NCN method designed for milk is used directly on retentate samples. An improved NCN sample preparation procedure for the Kjeldahl analysis that is designed for retentates is needed.

Retentate $\boldsymbol{p H}$. The $\mathrm{pH}$ of both the starting materials and retentates (Table 5) increased with increasing stage $(P<0.05)$. The starting material for stage 1 was skim milk, for stage 2 it was the MF retentate from stage 1 diluted with 2 parts RO water to 1 part reten- tate by weight, and for stage 3 it was the MF retentate from stage 2 diluted with 2 parts RO water to 1 part retentate by weight. Milk had a $\mathrm{pH}$ of about 6.6 at $50^{\circ} \mathrm{C}$ because of the presence of buffers such as citric acid and soluble minerals. Concentration of these buffers in the permeate portion of the retentate is the same as the feed for stage 1, and very little difference was found in $\mathrm{pH}$ of the starting material and the $3 \times$ retentate for stage 1 . Before each subsequent stage, retentate was diluted with $\mathrm{RO}$ water, resulting in a slight increase in $\mathrm{pH}$ of both the starting material and the retentate from that stage. The $\mathrm{pH}$ of the pasteurized $\mathrm{RO}$ water used to dilute the retentate was 6.83 and this, combined with dilution of the concentration of buffering salts in the second and third stages, caused the $\mathrm{pH}$ of the MF retentates to increase $(P<0.05)$ with stage.

Retentate Color and Particle Size. The L-value for retentates (Table 6$)$ increased $(P<0.05)$ with increasing stage, indicating that the retentate was getting whiter; a-values got less negative, indicating that the sample was less green; and b-values got more negative, meaning the sample was becoming more blue or less yellow $(P<0.05)$. Typical color values for skim, $1 \%$ fat, and $2 \%$ fat milk (Phillips et al., 1995) are also shown in Table 6 . The L-values and a-values of retentates became more similar to $2 \%$ fat milk as the

Table 5. Mean $(\mathrm{n}=4) \mathrm{pH}$ values $\left(50^{\circ} \mathrm{C}\right)$ of the starting material and final retentate from each stage of the 3-stage uniform transmembrane ceramic microfiltration $(\mathrm{MF})$ system

\begin{tabular}{lcc}
\hline MF stage & $\begin{array}{c}\text { Starting } \\
\text { material }\end{array}$ & Retentate \\
\hline Stage 1 & $6.62^{\mathrm{c}}$ & $6.58^{\mathrm{c}}$ \\
Stage 2 & $6.82^{\mathrm{b}}$ & $6.81^{\mathrm{b}}$ \\
Stage 3 & $7.01^{\mathrm{a}}$ & $6.97^{\mathrm{a}}$ \\
$\mathrm{SE}$ & 0.05 & 0.02 \\
$\mathrm{R}^{2}$ & 0.86 & 0.97 \\
\hline
\end{tabular}

${ }^{\mathrm{a}-\mathrm{c}}$ Means in the same column not sharing a common superscript are different $(P<0.05)$. 
Table 6. Mean $(\mathrm{n}=4)$ Hunter $\mathrm{L}$, a, b color values for retentates from each stage of the 3-stage uniform transmembrane ceramic microfiltration (MF) system

\begin{tabular}{lccc}
\hline MF stage & L-value & a-value & b-value \\
\hline Stage 1 & $78.28^{\mathrm{c}}$ & $-4.57^{\mathrm{c}}$ & $3.41^{\mathrm{a}}$ \\
Stage 2 & $79.09^{\mathrm{b}}$ & $-4.40^{\mathrm{b}}$ & $0.81^{\mathrm{b}}$ \\
Stage 3 & $80.07^{\mathrm{a}}$ & $-3.97^{\mathrm{a}}$ & $-0.16^{\mathrm{c}}$ \\
SE & 0.051 & 0.018 & 0.025 \\
$\mathrm{R}^{2}$ & 0.99 & $>0.99$ & $>0.99$ \\
& & & \\
Skim milk $^{1}$ & 73.77 & -6.68 & 1.13 \\
$1 \%$ milk $^{1}$ & 78.92 & -4.54 & 2.55 \\
$2 \%$ milk $^{1}$ & 81.11 & -3.74 & 2.99 \\
\hline
\end{tabular}

${ }^{\mathrm{a}-\mathrm{c}}$ Means in the same column not sharing a common superscript are different $(P<0.05)$.

${ }^{1}$ Data from Phillips et al. (1995).

number of stages increased, even though the fat content of the third-stage MF retentates was typically between 0.2 and $0.3 \%$. The L-value increased with stage because compounds in the permeate portion of the milk that provide a green and blue color to skim milk are being removed (i.e., MF permeate has a green color). The increase in $\mathrm{CN}$ concentration with increasing stage (Table 4) would also be expected to increase whiteness of the retentate due to increased light scattering. The particle size distribution (within the limits of the laser light scattering method we used) did not change between stages. The mean $\mathrm{D}[0.9]$ was $0.22 \mu \mathrm{m}$ and the $\mathrm{D}[4,3]$ was $0.16 \mu \mathrm{m}$. We could not detect a change in size of CN micelles due to processing, or changes in the composition of the water phase surrounding the CN micelles. Thus, the MF retentate could be used as a beverage ingredient to provide some of the desirable appearance of milk containing fat without the nondairy ingredients that are sometimes used to increase whiteness (Phillips and Barbano, 1997).

\section{SP Removed}

The theoretical percentage removal of SP by stage for a $3 \times, 3$-stage MF process is shown in Table 7 . Removal of SP during MF can be influenced by many factors (Hurt and Barbano, 2010). In the present study, the TP content of MF permeate was used as an estimate of SP content with the assumption that there was no $\mathrm{CN}$ in the MF permeate. When TP values for SP concentration in permeate were used, the calculated SP removal by the 3 -stage process was $104.31 \%$ (Table 7 ). The SDS-PAGE analysis of stage 1, 2, and 3 retentates indicates that not all SP was removed from the retentates, but a progressive reduction with increasing stage in SP content of the retentate is apparent in Figure 1. It also can be seen from the SDS-PAGE analysis of the MF permeate from the first stage (Figure 2) that MF permeate contains some $\mathrm{CN}$, so the assumption we made - that all the TP in the permeate was $\mathrm{SP}$ - was incorrect. Therefore, a sensitivity analysis is presented in Table 7 to demonstrate how much influence the presence of $0.01,0.02$, and $0.03 \% \mathrm{CN}$ in $\mathrm{MF}$ permeate would have on the expected SP removal by stage and total SP removal. In subsequent work (data not reported), we have found (by Kjeldahl analysis of MF permeates) that the CN content of MF permeate from our ceramic UTP system is typically between 0.02 and $0.03 \%$. Therefore, the SP removal achieved in the current project with a $3 \times, 3$-stage UTP MF process using ceramic membranes was probably between 95 and $98 \%$, as shown in Table 7.

A measure of the productivity and efficiency of an MF process for removal of SP from skim milk in the context of a manufacturing facility may be best expressed as kilograms of SP removed per square meter of membrane surface area per hour within each stage. The data from the current study are presented in that

Table 7. Sensitivity analysis for mean $(\mathrm{n}=4)$ serum protein removal $(\%)$ as percentage of serum protein $(\mathrm{SP})$ in starting skim milk determined by Kjeldahl analysis from each stage of the 3-stage uniform transmembrane ceramic microfiltration (MF) system, with different assumed amounts of casein (percentage by weight) in the permeate

\begin{tabular}{lccccc}
\hline & \multicolumn{5}{c}{ Assumed casein in the permeate $(\% \mathrm{wt} / \mathrm{wt})$} \\
\cline { 2 - 5 } MF stage & $0.00^{1}$ & 0.00 & 0.01 & 0.02 & 0.03 \\
\hline Stage 1 & 68 & $67.2^{\mathrm{a}}$ & $66.0^{\mathrm{a}}$ & $64.8^{\mathrm{a}}$ & $63.7^{\mathrm{a}}$ \\
Stage 2 & 22 & $24.9^{\mathrm{b}}$ & $23.9^{\mathrm{b}}$ & $22.9^{\mathrm{b}}$ & $21.9^{\mathrm{b}}$ \\
Stage 3 & 7 & $122^{\mathrm{c}}$ & $11.4^{\mathrm{c}}$ & $10.5^{\mathrm{c}}$ & $9.7^{\mathrm{c}}$ \\
Total removal & 97 & 104.3 & 101.3 & 98.3 & 95.2 \\
SE & - & 0.19 & 0.19 & 0.18 & 0.18 \\
$\mathrm{R}^{2}$ & & $>0.99$ & $>0.99$ & $>0.99$ & $>0.99$ \\
\hline
\end{tabular}

${ }^{\mathrm{a}-\mathrm{c}}$ Means in the same column not sharing a common superscript are different $(P<0.05)$.

${ }^{1}$ Data in this column represent theoretical SP removal, assuming no rejection of serum proteins and complete rejection of casein (i.e., $0.00 \%$ casein). 
Table 8. Mean $(\mathrm{n}=4)$ kilograms of serum protein $(\mathrm{SP})$ removed by each stage of the 3-stage uniform transmembrane ceramic microfiltration (MF) system measured by Kjeldahl

\begin{tabular}{lcc}
\hline MF stage & $\begin{array}{c}\text { SP removed } \\
\left(\mathrm{kg} / \mathrm{m}^{2} \text { per hour }\right)\end{array}$ & $\begin{array}{c}\text { Adjusted SP } \\
\text { removed }^{1} \\
\left(\mathrm{~kg} / \mathrm{m}^{2} \text { per hour }\right)\end{array}$ \\
\hline Stage 1 & $0.31^{\mathrm{a}}$ & $0.30^{\mathrm{a}}$ \\
Stage 2 & $0.12^{\mathrm{b}}$ & $0.11^{\mathrm{b}}$ \\
Stage 3 & $0.07^{\mathrm{c}}$ & $0.06^{\mathrm{c}}$ \\
SE & 0.0037 & 0.0033 \\
$\mathrm{R}^{2}$ & $>0.99$ & $>0.99$ \\
\hline
\end{tabular}

${ }^{\mathrm{a}-\mathrm{c}}$ Means in the same column not sharing a common superscript are different $(P<0.05)$.

${ }^{1}$ Adjusted for an assumed $0.02 \%$ casein in the permeate.

form in Table 8 . The mass SP removal decreased progressively with increasing stage $(P<0.05)$, which was expected. The presence of $0.02 \% \mathrm{CN}$ contamination does not have much effect on the estimate of the mass removal of SP per meter square of membrane per hour (Table 8).

\section{Challenges in Measuring SP Removal}

Removal of SP can be calculated using several different methods, such as from Kjeldahl analysis of the starting skim milk and the retentates of each stage, from Kjeldahl analysis of starting skim milk and the permeates as shown in Table 7, or from SDS-PAGE analysis of the retentates. All of these methods were subject to errors that influenced the calculated SP removal. It is important to understand the specific factors and sources of error important for each approach, and how they influenced the calculated SP removal. We concluded that the best estimate of SP removal was based on calculation of the mass of SP in the pasteurized skim milk before MF determined by Kjeldahl minus the mass of SP in the MF permeate determined by Kjeldahl. Two major factors in our work caused uncertainty in the accuracy of our estimation of SP removal with the mass-balance approach: (1) separate errors in estimates of masses of permeate and retentate because of the changeover from water to milk at start up and due to the residual retentate and permeate left in the system when ending a run, and (2) the unmeasured level of contamination of permeate with casein, which would cause an overestimate of SP removal. To estimate the bias error caused by the mass balance issues mentioned above, NPN removal was calculated in 2 ways. The Kjeldahl NPN method is a chemical reference method and works well on both retentate and permeate. The first way was based on the mass of permeate removed in each stage, and the second way was by using only the composition of the retentates produced in each stage.
The difference between the removal calculated both ways should give an estimate of the error caused by the mass balance issues. For NPN, the cumulative thirdstage removal calculated using mass of permeate and NPN composition of the permeates was $93.70 \pm 1.06 \%$, and NPN removal calculated using only analysis of the retentates and mass of retentate was not significantly different $(P>0.05)$ at $92.40 \pm 1.06 \%$. The fact that no difference in these 2 estimates of NPN removal based on NPN was detected indicates that any bias error in estimates of mass between permeate and retentate estimates did not create a significant bias in the estimate of SP removal data using only milk and permeate mass. The possible inclusion of some casein in the estimate of serum protein content of the MF permeate would cause an overestimation of SP removal. A sensitivity analysis to demonstrate the potential effect of this on our estimate of SP removal is shown in Table 7. Based on data for casein content of MF permeate collected on samples after this study was completed, we concluded that $0.02 \%$ protein of the protein measured in permeate

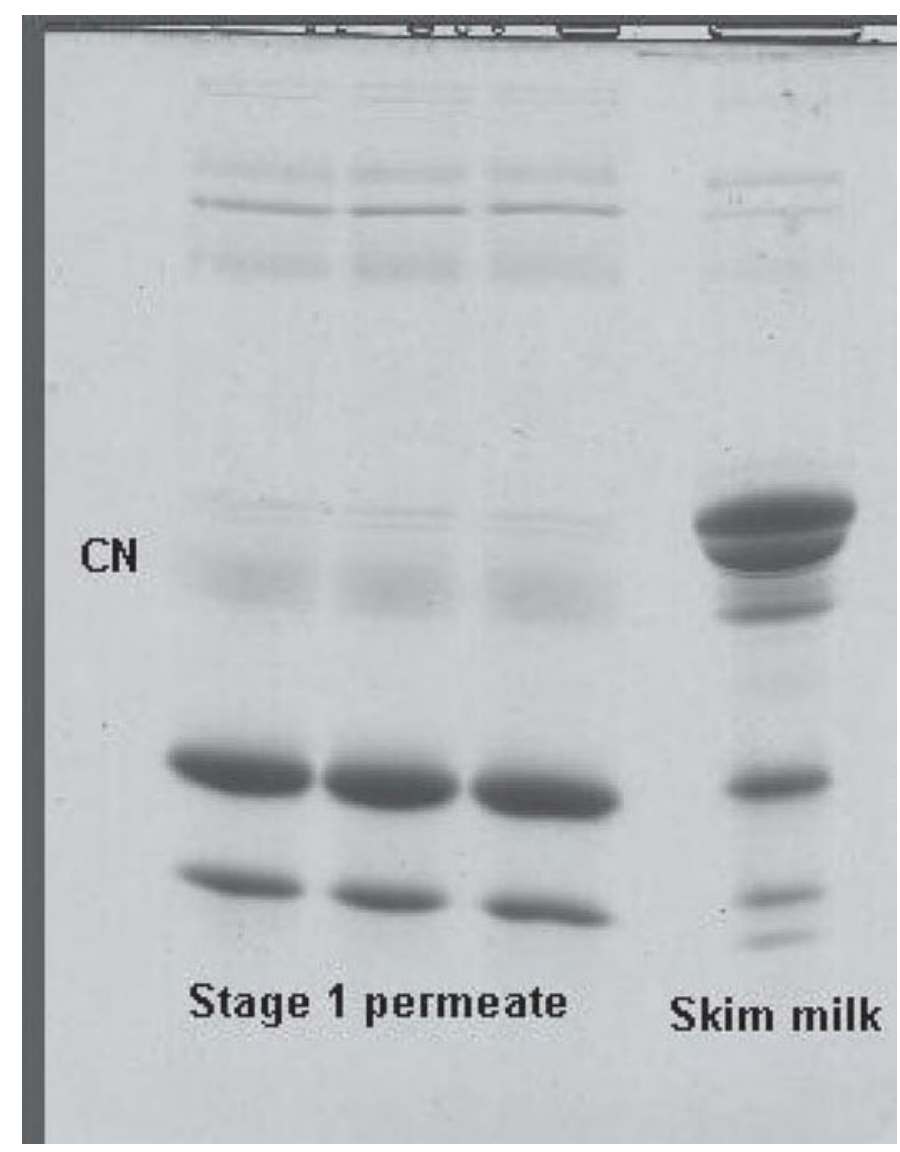

Figure 2. An SDS-PAGE gel for separation of proteins in skim milk and the microfiltration permeates produced by ceramic uniform transmembrane pressure process. 
Table 9. Mean \pm 1 standard deviation $(\mathrm{n}=4)$ relative percentage serum protein $(\mathrm{SP})$ reduction in microfiltration (MF) retentate by each stage of the 3-stage uniform transmembrane ceramic MF system measured by SDSPAGE and Kjeldahl

\begin{tabular}{lcccc}
\hline MF stage & $\begin{array}{c}\text { Theoretical } \\
\text { cumulative } \\
\text { SP reduction }\end{array}$ & $\begin{array}{c}\text { Cumulative } \\
\text { SP reduction } \\
\text { (SDS-PAGE) }\end{array}$ & $\begin{array}{c}\text { Cumulative } \\
\text { SP reduction }\end{array}$ & $\begin{array}{c}\text { Cumulative } \\
\text { SP reduction }^{2}\end{array}$ \\
\hline Stage 1 & 68 & $72.4^{\mathrm{a}} \pm 3.0$ & $54.6^{\mathrm{c}} \pm 2.8$ & $64.8^{\mathrm{b}} \pm 0.8$ \\
Stage 2 & 90 & $88.9^{\mathrm{a}} \pm 3.5$ & $72.4^{\mathrm{b}} \pm 0.8$ & $87.8^{\mathrm{a}} \pm 1.6$ \\
Stage 3 & 97 & $91.3^{\mathrm{b}} \pm 3.7$ & $78.6^{\mathrm{c}} \pm 1.0$ & $98.3^{\mathrm{a}} \pm 2.3$ \\
\hline
\end{tabular}

${ }^{\mathrm{a}-\mathrm{c}}$ Means in the same row not sharing a common superscript are different $(P<0.05)$.

${ }^{1}$ Measured by Kjeldahl on retentates.

${ }^{2}$ Measured by Kjeldahl on permeates assuming $0.02 \%$ casein in permeates.

is casein, not serum protein, and SP removal calculations were adjusted by subtracting $0.02 \%$ from the TP concentration in the permeates from each stage to give an estimate for the SP concentration in the permeate. Other sources of error in our study would be random errors, which were taken into account in the ANOVA and reflected in the values for standard error reported in each data table.

SP Removal Estimated by Kjeldahl Analysis of Retentates. The SP removal calculated using data obtained from Kjeldahl analysis of the retentates is shown in Table 9. The SP removal calculated from data obtained by Kjeldahl analysis of retentates was lower than that calculated using either Kjeldahl analysis of permeates or SDS-PAGE analysis of retentates. This was expected because the NCN Kjeldahl method designed for milk, when applied to $3 \times$ MF retentate, fails to precipitate all the $\mathrm{CN}$ in the retentate, which leads to an overestimation of $\mathrm{NCN}$ and thus $\mathrm{SP}$ in retentates. Research is need to modify the Kjeldahl NCN method to provide accurate estimates of NCN content of milks and retentates with much higher protein content than is typically found in bovine milks.

SP Removal Estimated by Kjeldahl Analysis of Permeates. Calculating SP removal using data from the Kjeldahl analysis of permeates required measurement of the mass of permeate produced in each stage. A source of error associated with this method is caused by difficulties in measuring the weight of retentate and permeate because of hold-up volumes in the processing equipment of retentate and permeate and the transition from water to milk at the water in the MF equipment at the beginning of the processing run. The calculation of SP removal with data obtained from Kjeldahl analysis of the permeates is influenced by loss of feed, retentate, and permeate during each of the 3 stages. Loss occurs at start-up for each stage, shutdown for each stage, and between stages. At start-up for each stage, some feed material is lost as hold up in the heat exchanger and pump used to bring the feed to $50^{\circ} \mathrm{C}$. Material is also lost in the first $14 \mathrm{~kg}$ of retentate and
$31 \mathrm{~kg}$ of permeate discarded, although most of the mass is water in the system at start-up. Some dilution of the collected retentate and permeate occurs because not all of the water is removed in the discarded fraction. At shutdown, the material remaining in the system and feed tank is lost. The loss associated with start-up and shutdown averaged $64 \pm 1.70 \mathrm{~kg}$. Additional loss averaging $4.40 \pm 0.76 \mathrm{~kg}$ occurs due to the transfer of the retentate between stages. The estimate of percentage SP removal by Kjeldahl analysis of permeates was higher $(P<0.05)$ than the estimate of percentage SP removal by Kjeldahl analysis of retentates for all stages (Table 9). In calculating mass-based SP removal, the denominator for each stage was the SP in the skim milk times the mass of skim milk, and the numerator was the mass of permeate times SP concentration in the permeate for that stage. In stages 2 and 3 , the feed mass was less than the initial mass of milk, meaning that the mass of permeate from these stages was lower than if no product had been lost and the feed volume for each stage was constant. This would suggest that SP removal was underestimated.

Analytical issues also exist with the Kjeldahl analysis that could influence calculation of SP removal. The SP concentration of the skim milk was used in the calculation of SP removal for all 3 stages; any error in the SP measured by Kjeldahl would have a large effect on calculated SP removal. A factor of 6.38 was used to convert nitrogen values into percentage protein, and this value was 6.37 for $\beta-\mathrm{LG}$ and 6.14 for $\alpha$-LA (Karman and van Boekel, 1986). However, the calculated percentage $\mathrm{SP}$ removal is a ratio of the calculated $\mathrm{SP}$ in the permeate divided by the calculated SP in the skim milk, so the nitrogen to protein conversion factor used does not matter when calculating the relative percentage SP reduction. However, the calculation of the mass of SP removed per unit surface area of MF membrane per hour (as in Table 8) would be influenced by the assumption of a 6.38 Kjeldahl factor for the SP.

A factor that would cause the SP removal estimate by Kjeldahl analysis of MF permeates to be too high 
would be contamination of the MF permeate with casein and counting the casein as SP. This issue was addressed in Table 7 and reflected in Table 9. Based on analysis of MF permeates produced by this processing system after completion of the present study, it was found that the equivalent of about $0.02 \%$ true protein in the MF permeates was due to $\mathrm{CN}$, not SP (data not shown). A sensitivity analysis to demonstrate the effect of low levels of $\mathrm{CN}$ in the permeate on the estimation of SP removal was presented in Table 7 , and the results of that sensitivity analysis are reflected in the data presented in Table 7.

If the skim milk had undergone more heat treatment during pasteurization, then the amount of SP in milk determined with Kjeldahl would be lower because some $\mathrm{SP}$ would be associated with the $\mathrm{CN}$ micelles (Harland et al., 1952) and counted by the Kjeldahl method as if it were CN (Lynch et al., 1998). Bound SP would not be removed during MF and thus would not change the estimate of percentage of SP removal determined by using Kjeldahl analysis. However, SDS-PAGE analysis of the retentate would cause dissociation of the CN-SP complex and indicate higher than expected levels of SP in retentate and would be expected to underestimate the removal of SP that was available to be removed. In our study, we tried to minimize heat denaturation of SP by keeping the HTST pasteurization temperature and time near the minimum.

SP Removal Estimated by SDS-PAGE Analysis of Retentates. The SP removal calculated using SDS-PAGE analysis of MF retentates and the starting skim milk are shown in Table 9. No use of mass data collected during milk processing was required for this calculation; therefore, any errors associated with estimates of masses of skim milk, retentate, or permeate were not an issue in these calculations. The SP removal calculated using this method was subject to several different sources of error than were found in the approach using Kjeldahl. The retentates from each stage have a high concentration of CN compared with $\mathrm{SP}$, which means that the CN could be in the nonlinear range of detector response due to the large amount of $\mathrm{CN}$ loaded on the gel in a slot. On the other hand, the SP bands could be below the limits of quantification for the detector. The problem of limit of quantification for SP was especially true in later MF stages when the concentration of SP in the retentates was very low. Using SDS-PAGE analysis to calculate SP removal was subject to more errors and limitations than the Kjeldahl mass balance methods.

\section{CONCLUSIONS}

Theoretically, a 3-stage, $3 \times$ MF process could remove $97 \%$ of the SP from skim milk, with a cumulative SP removal of 68 and $90 \%$ after the first and second stages respectively. The cumulative SP removal using a 3-stage, $3 \times$ MF process with a UTP system with $0.01-\mu \mathrm{m}$ ceramic membranes in this experiment was $64.8 \pm 0.8,87.8 \pm 1.6$, and $98.3 \pm 2.3 \%$ for the first, second, and third stages, respectively, when SP removal was calculated using the mass of SP removed in the permeate of each stage. Various methods of calculation of SP removal were evaluated. Given the analytical limitations in the various methods for measuring SP removal, calculation of SP removal based on the mass of SP in the skim milk (determined by Kjeldahl) and the mass SP present in all of the permeate produced by the process (determined by Kjeldahl) provided the best estimate of SP removal for a MF process.

\section{REFERENCES}

AOAC. 2000. Official Methods of Analysis. 17th ed. AOAC, Gaithersburg, MD.

Belfort, G., R. H. Davis, and A. L. Zydney. 1994. The behavior of suspensions and macromolecular solutions in crossflow microfiltration. J. Membr. Sci. 96:1-58.

Britten, M., and Y. Pouliot. 1996. Characterization of whey protein isolate obtained from milk microfiltration permeate. Lait 76:255265.

Cheryan, M. 1998. Ultrafiltration and Microfiltration Handbook. Technomic Publishing Company Inc., Lancaster, PA.

de Wit, J. N., and G. Klarenbeck. 1984. Effects of various heat treatments on structure and solubility of whey proteins. J. Dairy Sci. 67:2701-2710.

Evans, J., J. Zulewska, M. Newbold, M. A. Drake, and D. M. Barbano. 2009. Comparison of composition, sensory and volatile components of thirty-four percent whey protein and milk serum protein concentrates. J. Dairy Sci. 92:4773-4791.

Harland, H. A., S. T. Coulter, and R. Jenness. 1952. The effect of the various steps in the manufacture on the extent of serum protein denaturation in nonfat dry milk. J. Dairy Sci. 35:363-368.

Holt, C. 1992. Structure and stability of bovine casein micelles. Adv. Protein Chem. 43:63-151.

Hurt, E., and D. M. Barbano. 2010. Processing factors that influence casein and serum protein separation by microfiltration. J. Dairy Sci. 93:4928-4941.

Karman, A. H., and M. A. J. S. van Boekel. 1986. Evaluation of the Kjeldahl factor for conversion of the nitrogen-content of milk and milk products to protein content. Neth. Milk Dairy J. 40:315336.

Kaylegian, K. E., G. E. Houghton, J. M. Lynch, J. R. Fleming, and D. M. Barbano. 2006. Calibration of infrared milk analyzers: Modified milk versus producer milk. J. Dairy Sci. 89:2817-2832.

Le Berre, O., and G. Daufin. 1996. Skimmilk crossflow microfiltration performance versus permeation flux to wall shear stress ratio. J. Membr. Sci. 117:261-270.

Lynch, J. M., D. M. Barbano, and J. R. Fleming. 1998. Indirect and direct determination of the casein content of milk by Kjeldahl nitrogen analysis: Collaborative study. J. AOAC Int. 81:763-774. 
Ma, Y., C. Ryan, D. M. Barbano, D. M. Galton, M. A. Rudan, and K. J. Boor. 2000. Effects of somatic cell count on quality and shelf-life of pasteurized fluid milk. J. Dairy Sci. 83:264-274.

Nelson, B. K., and D. M. Barbano. 2005. A microfiltration process to maximize removal of serum protein from skim milk before cheese making. J. Dairy Sci. 88:1891-1900.

Papadatos, A., M. Neocleous, A. M. Berger, and D. M. Barbano. 2003. Economic feasibility of microfiltration of milk prior to cheesemaking. J. Dairy Sci. 86:1564-1577.

Phillips, L. G., and D. M. Barbano. 1997. The influence of fat substitutes based on protein and titanium dioxide on the sensory properties of lowfat milks. J. Dairy Sci. 80:2726-2731.

Phillips, L. G., M. L. McGiff, D. M. Barbano, and H. T. Lawless. 1995. The influence of fat on the sensory properties, viscosity, and color of low fat milk. J. Dairy Sci. 18:1258-1266.

Pierre, A., J. Fauquant, Y. Le Graet, M. Piot, and J. L. Maubios. 1992. Native micellar casein separation through cross-flow membrane microfiltration. Lait 72:461-474.
Quinones, H. J., D. M. Barbano, and L. G. Philips. 1998. Influence of protein standardization by ultrafiltration on the viscosity, color, and sensory properties of 2 and 3.3\% milks. J. Dairy Sci. 81:884894.

Sachdeva, S., and W. Buchheim. 1997. Separation of native casein and whey proteins during crossflow microfiltration of skim milk. Aust. J. Dairy Technol. 52:92-97.

Sandblom, R. M. inventor. 1978. Filtering process. Alfa-Laval AB, assignee. US Pat. No. 4,105,547.

Verdi, R. J., D. M. Barbano, and M. E. Dellavalle. 1987. Variability in true protein, casein, nonprotein nitrogen, and proteolysis in high and low somatic cell count milks. J. Dairy Sci. 70:230-242.

Walstra, P., T. J. Geurts, A. Noomen, A. Jallema, and M. A. J. S. van Boekel. 1999. Dairy Technology: Principles of Milk Properties and Processes. Marcel Dekker Inc., New York, NY.

Zulewska, J., M. Newbold, and D. M. Barbano. 2009. Efficiency of serum protein removal from skim milk with ceramic and polymeric membranes at $50^{\circ} \mathrm{C}$. J. Dairy Sci. 92:1361-1377. 